\title{
RHIC Beam Abort Kicker Power Supply System Commissioning Experience and Remaining Issues*
}

\author{
W. Zhang, L. A. Ahrens, J. Mi, B. Oerter, R. Sanders and J. Sandberg \\ Collider-Accelerator Department, Brookhaven National Laboratory, Upton, NY 11973
}

\section{Abstract}

The RHIC Beam Abort Kicker Power Supply Systems commissioning experience and the remaining issues will be reported in this paper. The RHIC Blue Ring Beam Abort Kicker Power Supply System initial commissioning took place in June 1999. Its identical system in Yellow Ring was brought on line during Spring 2000. Each of the RHIC Beam Abort Kicker Power Supply Systems consists of five high voltage modulators and subsystems. These systems are critical devices for RHIC machine protection and environmental protection. They are required to be effective, reliable and operating with sufficient redundancy to safely abort the beam to its beam dump at the end of accumulation or at any time when they are commanded. To deflect $66 \mathrm{GeV}$ ion beam to the beam absorbers, the RHIC Beam Abort Kicker Power Supply Systems were operated at $22 \mathrm{kV}$ level. The RHIC 2000 commissioning run was very successful.

\section{INTRODUCTION}

The RHIC beam abort kicker systems for Blue and Yellow ring were received for beam commission and operation in June 1999. The sole purpose of these systems is to remove beam from RHIC and safely dispose the beam onto internal beam dump absorbers. At RHIC injection energy, environmental protection from beam radiation is the main concern. At top energy of $100 \mathrm{GeV} / \mathrm{u}$, the concerns include not only radiation, but also possible damage to the expensive detectors and super-conducting magnets.

The two beam abort kicker systems, for Blue and Yellow ring, are identical. Each consists of five high voltage modulators, five magnet sections, and a central control and auxiliary system [1]. Table 1 lists the main parameter specifications of the RHIC Beam Abort Kicker Systems.

Table 1 Main Parameter Specifications

\begin{tabular}{|l|l|}
\hline RHIC Magnetic Rigidity & $97.5 \mathrm{~T}-\mathrm{m}$ to $839.5 \mathrm{~T}-\mathrm{m}$ \\
\hline Top Kinetic Energy for $\mathrm{Au}$ & $100 \mathrm{GEC} / \mathrm{u}$ \\
\hline Top Kinetic Energy for $\mathrm{p}$ & $250 \mathrm{GeV}$ \\
\hline Beam Gap for Abort & $\sim 1 \mu \mathrm{S}$ \\
\hline Magnet Length & $1.22 \mathrm{~m}$ per section \\
\hline
\end{tabular}

\footnotetext{
* Work performed under the auspices of the U.S. Dept. of Energy.
}

\begin{tabular}{|l|l|}
\hline Magnet Horizontal Aperture & $50.8 \mathrm{~mm}$ \\
\hline Magnet Vertical Aperture & $76.2 \mathrm{~mm}$ \\
\hline Number of Magnet Sections & 5 per ring \\
\hline $\begin{array}{l}\text { Deflection Angle at Top } \\
\text { Energy }\end{array}$ & 1.7 to $2.5 \mathrm{mrad}$ \\
\hline $\begin{array}{l}\text { Nominal Magnetic Field at } \\
\text { Top Energy }\end{array}$ & $0.22 \mathrm{~T}$ \\
\hline Pulse Duration & $>12.6 \mu \mathrm{S}$ \\
\hline Pulse Rise Time & $<1 \mu \mathrm{S}$ \\
\hline Pulse Fall Time & Not Applicable \\
\hline PFN voltage & $33 \mathrm{kV}$ maximum \\
\hline Magnet Current & $21 \mathrm{kA}$ maximum \\
\hline
\end{tabular}

The high voltage modulators are located inside the RHIC tunnel, and directly attached to their magnet sections. The Blue Ring Modulators and magnet chamber are located in RHIC tunnel section 10 outer ring, and the Yellow Ring Modulators and magnet chamber are located in section 9 outer ring.

Figure 1 is a picture of one of the RHIC Beam Abort Kicker System high voltage modulators, and figure 2 shows the typical waveforms of the magnet current.

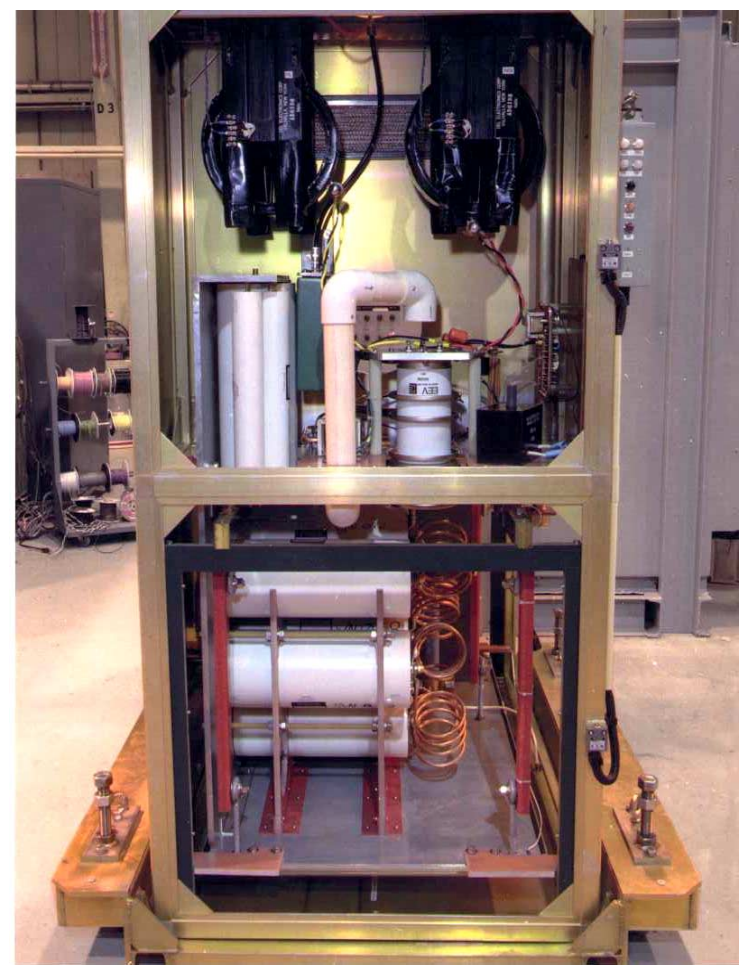

Figure 1. The RHIC Beam Abort Kicker High Voltage Modulator. 


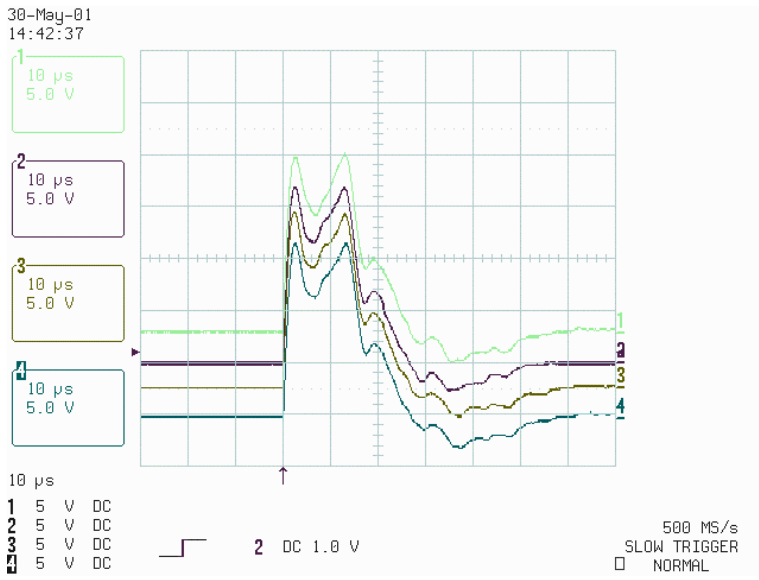

Figure 2. The magnet current waveforms of the RHIC Blue Ring Beam Abort Kicker System.

The magnet current of the RHIC Beam Abort Kicker systems shall track the beam energy during injection, acceleration and storage. A reference level proportional to the current in the RHIC main dipole is supplied to the voltage programming input of the charging high voltage power supply. At injection energy, the modulator PFNs are pre-charged to about $4 \mathrm{kV}$, and stay in this level while the RHIC ring is filled with beam. The acceleration to the top energy is about 57 seconds or longer, and the power supply tracks the acceleration curve within 5\% range at any given time. During the beam storage, the PFN voltage is regulated to maintain the DC voltage level corresponding to the beam energy until the end of the storage. The kicker aborts the beam to the internal beam dump upon receiving an abort command trigger. The designed storage time of RHIC is 10 hours.

\section{COMMISSIONING EXPERIENCE}

The initial commissioning of RHIC, during summer 1999, was at low energy and low intensity. Therefore, the required voltage of beam abort kicker system for initial commissioning was well below specified maximum. The Blue Ring Beam Abort Kicker System was tested up to the recommended voltage of $22 \mathrm{kV}$, about two third of the specified maximum operation voltage of $33 \mathrm{kV}$. Several factors limited the Blue ring beam abort kicker system testing. One was that the magnets were waiting to be baked under high vacuum, and ferrite out gassing would cause arcing above $22 \mathrm{kV}$. Secondly, the Blue Ring Beam Abort Kicker Modulators were pulse-tested only at $26 \mathrm{kV}$ for about one hour each prior of installation, and one unit had arced at that voltage level. Third reason was due to the absence of the critical protection subsystem of the voltage monitoring, current monitoring and fault interlock modules. The Blue Ring Beam Abort Kicker System was kept running at injection energy level, about $4 \mathrm{kV}$, off the time line through entire RHIC 1999 Commission run.

The Yellow Ring Beam Abort Kicker System was commissioned during year 2000. Three of the five high voltage modulators were pulse-tested and four were DC hi-potted to 26 to $27 \mathrm{kV}$ with current transformer in place, before installation to $26 \mathrm{kV}$. After installation of the missing high voltage components of the modulators, the system was gradually brought up to $22 \mathrm{kV}$. The voltage was limited to below $27 \mathrm{kV}$ because two of the five CX1575C thyratrons were somewhat damaged prior to installation, and higher voltage might cause further damage to the thyratrons.

For the 2000 commissioning goal, beam $\gamma=70$, the 22 $\mathrm{kV}$ charging level is sufficient to deflect beam to its internal dump. Therefore, both Blue and Yellow ring systems were limited to operate below $22 \mathrm{kV}$ to protect thyratrons and other hardware from unnecessary harm. The magnets were baked under high temperature prior to the start of RHIC 2000 Commissioning, and performed well as designed.

The voltage monitoring and fault interlock buckets for both systems were assembled, tested and installed for the RHIC 2000 run. Many modifications have to be made due to original design deficiency.

To reach the RHIC 2001 Commissioning Goal, the five CX1575C thyratrons of the Yellow Ring Beam Abort Kicker Modulators have been replaced with higher rated CX3575C type. The thyratrons in the Blue Ring Beam Abort Kicker Modulators will be replaced gradually only when necessary, due to the high cost of thyratrons. The constant voltage transformers were added into AC lines to protect system from transient surges and to stabilize the thyratron auxiliary power supplies. Both Blue and Yellow ring beam abort kicker systems have been tested up to 27 $\mathrm{kV}$, which will be the maximum operation level for this commissioning period.

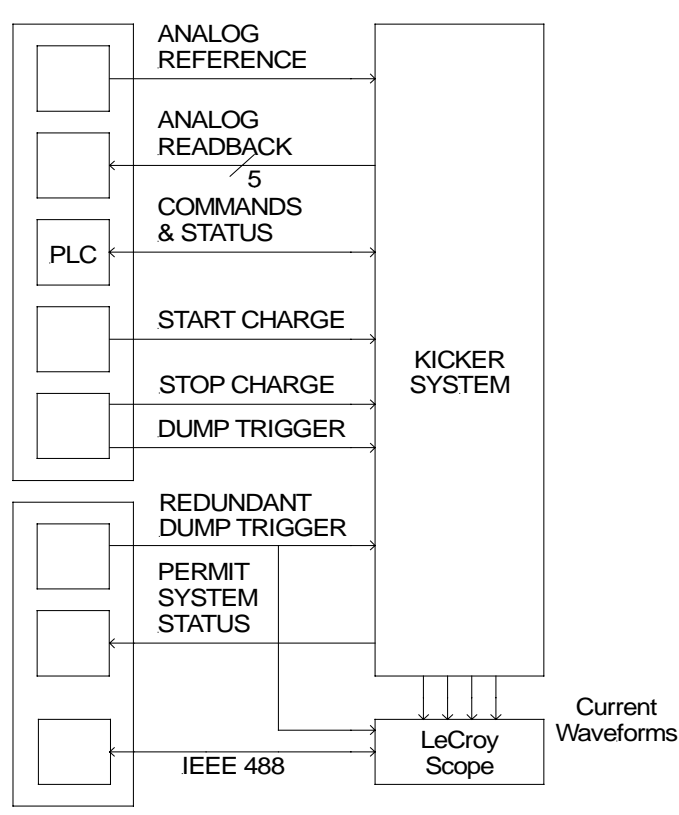

Figure 3. The control system block diagram. 
The system integration with remote control and local control has been a joint effort, since 1999, by many physicists, Control Section and Pulsed Power engineers and technicians, Main-Control-Room and Operation Support personnel. The block diagram of the present control configuration is shown in the Figure 3.

\section{REMAINING ISSUES}

The remaining issues include the thyratron premature firing [2], the high voltage pulsed capacitor oil leak, grounding noise, absence of the current monitoring and fault interlock, absence of the high current pulse drive on the thyratron grid one, etc.

In some occasions, two of the five modules of the Blue Ring Beam Abort System are having difficulty to hold off for ten hours under $27 \mathrm{kV}$ high voltage DC storage. This is due to thyratron premature firing or self-conduction. The CX $1575 \mathrm{C}$ is a hollow-anode thyratron primarily serving laser applications. It has a small anode cavity. The amount of electrons during forward conduction is sufficient for sub-micro-second reverse conduction, suitable for general laser applications. However, the RHIC Beam Abort kicker modulator circuit has a $40 \%$ reversal current and the reverse current last for more than $30 \mu \mathrm{S}$ duration. This is way beyond the capability of a small anode cavity. As a result, the forced reverse conduction cause metallic arcing which depleting the electrode and spotting thyratron inner surface wall with metallic material and reduce its hold off capability. The replacement tube $\mathrm{CX} 3575 \mathrm{C}$ has larger electrodes and higher voltage and current capabilities. It is expected to perform better than CX1575C. The initial test performed at the RHIC beam abort kicker test stand indicated the reverse conduction remain to be an issue. EEV has suggested using HX3002 gas switch for RHIC Beam Abort Kicker application. One HX3002 tube has been received and is waiting to be evaluated. The gas switch has better forward and reverse conduction property, but limited discharge lifetime. During the RHIC commissioning, the kicker is discharged frequently and mostly at injection energy and during acceleration ramp, below its peak value. The discharge rate had been as high as more than two hundred times a day, much higher than the specified once every ten hours. In the low current high discharge rate situation, the thyratron is preferable for the longer discharge lifetime.

For high rate of conduction in thyratron applications, a double-trigger approach, a high voltage trigger pulse to drive its bias grid and a high current trigger pulse to drive its prime grids, shall be used. This has the advantage of generating a large amount of plasma with high current trigger pulse for a rapid high current conduction and allowing higher DC thresh hold potential before pulse to reduce the chance of premature self conduction. The other advantage of double-trigger is for the pulse surety. The thyratron can be triggered with the presence of anyone of the triggers. This makes two triggers compliment each other in the event of missing one trigger. This feature is required in the RHIC Beam Abort Kicker design, but not materialized in the finished systems. Only an eight hundred-voltage trigger pulse per modulator is provided at this time. And, there is lack of physical space inside the modulators to add in the high voltage isolated pulse transformer and other hardware accessories for the high current trigger pulse. On the system level, there are two trigger chassis used in each system serves five modulators. One chassis has a DC power supply and two trigger generators, the other has one power supply and three trigger generators. In the event of trigger power supply failure, a set of two or three trigger generators and their related modulators will become un-operational. This problem has to be addressed. The plan is to add the third trigger chassis to bring up the total power supply to three units and the trigger generator to ten to twelve channels. Two high voltage pulse triggers from different chassis shall be combined to provide the trigger redundancy and enhance the system availability.

The scenario of premature firing of one or more pulser was not addressed in the original design. A fast re-trigger scheme using the magnet current read-back signals through a multi-channel RF combiner to trigger the rest of the modulators will be added. This will reduce the likelihood of beam-induced damage to the experiment detector and super-conducting magnets. The preliminary result shows a $2.5 \mu \mathrm{S}$ time difference of output currents. This is mainly due to the read-back cable delay, trigger output cable delay, thyratron ionisation time, etc.

A large quantity of mineral oil filled plastic case capacitors are used in the high voltage modulators. A few have leaked and failed during test and operation. The vaporized oil is ignitable and the mineral oil is not selfextinguishable. The plastic case material is also a fire hazard. The water sprinkler systems above the modulators have been modified as an enhanced fire protection measure.

The RHIC Beam Abort Kicker Systems will have to be further developed. It is our recommendation that a new design with advanced approach shall be investigated to achieve the present and future RHIC design requirements.

\section{REFERENCES}

[1] H. Hahn, et al., "The RHIC Beam Abort Kicker System", Proceedings of the 1999 Particle Accelerator Conference, 1999.

[2] H. Hahn, et al., "Operation of the RHIC Beam Dump Thyratron CX1575C", AD/RHIC/RD-127, August 1999. 